\title{
Effect of maternal dietary supplementation with phytosterol esters on muscle development of broiler offspring*
}

\author{
Leshan Wang1,"\#, XudongZuo1,\#, Weijie Zhao', Gan Zhou'1, Lv Luo1, Kelin Yang1', Gang Shu', \\ Songbo Wang1, Ping Gao', Xiaotong Zhu', Qingyan Jiang ${ }^{1,2}$ and Lina Wang ${ }^{1}$
}

'Guangdong Provincial Key Laboratory of Animal Nutrition Control, College of Animal Science, South China Agricultural University, Guangzhou 510640, Guangdong, People's Republic of China; 2National Engineering Research Center for the Breeding Swine Industry, South China Agricultural University, Guangzhou 510640, Guangdong, People's Republic of China

Recently, embryo muscle development, which is crucial for postnatal skeletal muscle growth, has been investigated widely. Nutrients in ovo were suggested to be critical in embryo muscle development since the chick growth mostly relies on nutrients in eggs at the early developmental stage. Phytosterol esters (PE), which are derived from the reactions between phytosterols and fatty acids, were demonstrated to have important effects on lipid and cholesterol metabolism regulation. In order to reveal the effect of maternal lipid metabolism on the deposition of nutrients in eggs and the development of embryonic muscles, broiler hens were fed with a diet supplemented with $5 \%$ PE or control diet. Lipid deposition in eggs and growth of the hatched chicks were studied. We found that PE increased bile acid (BA) deposition in the eggs and serum of hens $(p=0.02$ and $p<0.01$, respectively), altered insulin and glucose level differentially in female and male offspring, and promoted body weight ( $p=0.02$ for male and female on day 49 ), muscle fiber density ( $p=0.02$ for female on day 49 ), and myogenin and myogenic determination factor (myoD) expression ( $p=0.03$ and $p=0.02$ on day 49$)$ by the activation of $B A$ receptors in female, but not in male, offspring. Our study determined for the first time that PE promoted muscle development of chicks hatching from eggs laid by the hens, through regulating bile acid (BA) deposition and this may be attributed to the activation of $\mathrm{BA}$ receptors.

Keywords: bile acid, chicken, muscle, offspring, phytosterol ester

Received: 18 October, 2019; revised: 12 February, 2020; accepted: 21 February, 2020; available on-line: 19 March, 2020

$\bigotimes_{\text {e-mail: wanglina@scau.edu.cn }}$

\#These two authors contributed equally to the study

*Acknowledgements of Financial Suppoort: This study was supported by the National Natural Science Foundation of China (\#31790411, \#31101780 and \#31672464).

Abbreviations: BA, bile acid; CYP7A1, cholesterol 7a-hydroxylase; $F X R$, farnesoid $X$ receptor; IOF, in ovo feeding; $L R H-1$, liver receptor homolog1; $L X R$, liver $X$ receptor; $P E$, phytosterol esters; TBA, total bile acid; TGR5, G protein coupled bile acid receptor 1

\section{INTRODUCTION}

Chicken meat serves as the main source of animalderived protein for humans, especially in Western lifestyles. Nowadays, nutritional methods are used widely to improve chicken meat quality (Castro et al., 2018; Lai et al., 2018). The poultry skeletal muscle development is similar to that of mammals. After hatching, the total number of muscle fibers remains immutable, and hypertrophy occurs later. Unlike mammals, poultry obtain nutrients responsible for skeletal muscle development almost entirely from the fertilized eggs. In ovo feeding $(\mathrm{IOF})$ is regarded as an effective way to investigate the mechanism behind the regulatory role of different nutrients, although it is not applicable in poultry farming. Exogenous amino acids administered by IOF can delay muscle loss of late-term poultry embryos (Uni et al., 2005). It was also reported that IOF administration of carbohydrates can improve energy status, increase the hepatic glycogen content and enhance myofiber growth until day 35 in late-term embryos by increasing liver and muscle glycogen turnover and satellite cell proliferation (Kornasio et al., 2011). It is well known that egg yolks are rich in lipids and cholesterol. But it is still not clear whether the lipids, cholesterols or their metabolites have any effects on poultry embryo growth.

Phytosterol esters (PE), which are derived from the reactions between phytosterols and fatty acids, were demonstrated to have many beneficial functions in rodents, such as cholesterol- and triglyceride-lowering effects (Jain et al., 2008; Schonewille et al., 2014). Recent studies revealed that $\mathrm{PE}$ and soy protein increased the faecal excretion of $\mathrm{BA}$ compared to soy protein alone in hamsters, and dietary PE suppressed bile acid synthesis in patients (Lin et al., 2004; O’Neill et al., 2004). CYP7A1 is a rate-limiting enzyme in BA synthesis. FXR interacts with BA to inhibit CYP7A1 expression through a feedback loop while LXR promotes CYP7A1 expression with the help of other sterols and both need the participation of LRH-1 (Elizabeth, 2016). Chenodeoxycholic acid is one of the four types of BA in chickens which constitutes $80 \%$ of BAs. All of these BAs are taurine-conjugated and can be classified as primary and secondary BAs with distinct functions (Hofmann \& Hagey, 2014). Further studies showed that circulating deoxycholic acid content is associated with reduced skeletal muscle volume (Kobayashi et al., 2017). More specifically, by binding to farnesoid X receptor (FXR) or G proteincoupled bile acid receptor 1 (TGR5), different BA can impair or improve glucose homeostasis in the skeletal muscle (Li et al., 2016). Until now, few studies have associated the role of BA with the growth and development of skeletal muscle in poultry. Here, we hypothesize that BA can improve chicken muscle development and our results suggest that $\mathrm{PE}$, as a feed additive for hens, can increase the deposition of BA in eggs and eventually promote skeletal muscle growth and development of female offspring and this may be related to $\mathrm{BA}$ receptors (FXR or TGR5) activation and elevated myogenesis in the embryo. 


\section{MATERIALS AND METHODS}

Experimental materials and animals. The White Plymouth Rock chickens (LWS; Gallus gallus domesticus) in this study were obtained from Guangdong Wens Cantian Poultry Industry Group (Xinxing, China). The PE (a mixture containing 40\% $\beta$-sitosterol, 20\% stigmasterol, $10 \%$ campesterol) were purchased as a commercial product from Wuhan Xianghe Biological Technology Co., Ltd. (Wuhan, China).

Experimental design and sampling. Eighty White Rock breeder hens ( 150 days old) were randomly divided into 2 groups of 40 each. The hens in the first group were fed a basal diet, while the second group was fed a basal diet supplemented with 5\% PE for 4 weeks. The detailed composition of the basal diet was listed in Table 1 . In the last week, eggs were collected for TBA detection or further hatching. Liver and blood samples of the hens were collected for further analysis.

The hens were maintained in 80 separated cages (25.4 $\mathrm{cm}$ wide, $30.5 \mathrm{~cm}$ tall and $30.5 \mathrm{~cm}$ deep) with feed and water being supplied ad libitum. At the end of the trial, the hens were sacrificed by jugular vein bleeding and the left liver apexes were obtained for extraction of total RNA. All eggs were collected and marked in the fourth week at 6 PM, with at least 6 eggs per each hen. The eggs were selected randomly for $\mathrm{BA}$ detection $(n=8$ in each group), and the remaining eggs were then transported to a hatching facility ( $n=185$ in control and $n=174$ in PE group) at Can'Tian Hatchery (Xinxing, China). The eggs were weighed, marked and incubated according to

Table 1. The composition and nutrient content of the basal diet.

\begin{tabular}{|c|c|}
\hline Item & Percentage (\%) \\
\hline $\begin{array}{l}\text { Diet ingredients } \\
\text { Corn starch } \\
\text { Soybean, CP 43\% } \\
\text { Wheat } \\
\text { Wheat bran } \\
\text { Mountain flour } \\
\text { Calcium hydrophosphate } \\
\text { Sodium chloride } \\
\text { Sodium bicarbonate } \\
\text { Choline chloride } \\
\text { Mold inhibitor }{ }^{1} \\
\text { Mineral premix }{ }^{2} \\
\text { Vitamin premix } \\
\text { Calculated nutrient content } \\
\text { Digestible AA percentage } \\
\text { AME (MJ/kg) } \\
\text { Water }\end{array}$ & $\begin{array}{l}44.9 \\
25.5 \\
15.6 \\
2.70 \\
8.60 \\
1.10 \\
0.27 \\
0.20 \\
0.10 \\
0.1 \\
0.11 \\
0.04 \\
\\
2.6 \\
13.5 \\
11.9\end{array}$ \\
\hline Crude protein & 16.6 \\
\hline Crude fat & 6.08 \\
\hline Crude fiber & 2.63 \\
\hline Calcium & 3.50 \\
\hline Total phosphorus & 0.53 \\
\hline $\begin{array}{l}\text { Non-phytic phosphorus } \\
\text { Lysine } \\
\text { Methionine } \\
\text { Threonine } \\
\text { Arginine } \\
\text { Tryptophan }\end{array}$ & $\begin{array}{l}0.32 \\
0.90 \\
0.44 \\
0.61 \\
1.07 \\
0.19\end{array}$ \\
\hline
\end{tabular}

1Propionic acid, sodium hydroxide, calcium hydroxide, amorphous silicon dioxide, sorbic acid, benzoic acid, propylparaben, methylparaben and BHA. ${ }^{2}$ The premix supplied per kg of diet: $\mathrm{Cu}, 8 \mathrm{mg} ; \mathrm{Fe}, 80 \mathrm{mg} ; \mathrm{Mn}$, $100 \mathrm{mg}$; Zn, $60 \mathrm{mg}$; l, 0.50mg; Se, $0.40 \mathrm{mg}$; Co, $0.40 \mathrm{mg}$. ${ }^{3}$ The premix supplied per kg of diet: Vitamin A, 4000 IU; Vitamin B, 11 mg; Vitamin B2, 3 mg; Vitamin B5, 40 mg; Vitamin B6, 2 mg; Vitamin B12, 0.01 mg; Vitamin D3, 1000 IU; Vitamin E, $10 \mathrm{IU}$; Vitamin K, $32 \mathrm{mg}$; biotin, 0.05 $\mathrm{mg}$; folic acid, $0.5 \mathrm{mg}$; D-pantothenic acid, $6 \mathrm{mg}$; nicotinic, $20 \mathrm{mg}$; antioxidant, $100 \mathrm{mg}$. the standards $\left(37.5^{\circ} \mathrm{C}, 55 \%\right.$ humidity, with rotation). 133 control eggs and 125 maternal PE eggs were hatched, and the gender of hatched chicks was then identified. After one week the chicks were randomly selected, 120 chicks in each group (60 male and 60 female) were all fed basal diet (detailed information is provided in supplementary table 1) formulated by the hatchery and weighed on day 1, 21 and 49 after hatching. Additionally, on day 1 and 49, we collected samples from 20 chicks (10 male and 10 female) in each group. Specifically, the whole left legs were separated and weighed immediately and right legs were used for collecting the medium part of the gastrocnemius muscle, promptly frozen in liquid nitrogen and stored at $-80^{\circ} \mathrm{C}$ for further examination. A brief scheme of the experimental design is presented in Supplementary Fig. 1. at https://ojs.ptbioch.edu.pl/index.php/abp.

Sectioning and immunofluorescence staining. Gastrocnemius muscle (offspring on day 49) transverse cryosections were obtained from the mid-belly region of each sample at $10 \mu \mathrm{m}$ thickness in a cryostat microtome (Leica, Germany) at $-20^{\circ} \mathrm{C}$. Sections were then adhered to Superfrost Plus slides (Jinhua, China) and stored at $4^{\circ} \mathrm{C}$ for further examination (8 sections per sample). Prior to staining, slides were allowed to dry at room temperature for $10 \mathrm{~min}$. For staining, the slides were fixed in $4 \%(\mathrm{v} / \mathrm{v})$ paraformaldehyde for $5 \mathrm{~min}$, rinsed gently in PBS for $5 \mathrm{~min}$, and air-dried for $15 \mathrm{~min}$ in a biosafety cabinet. After being incubated in cell membrane staining reagent L9393 (Sigma-Aldrich, U.S.A.) for $20 \mathrm{~min}$, the slides were rinsed gently in PBS for 5 minutes. Finally, the images were captured using the Nikon Eclipse Ti-s microscopy system (Nikon Instruments, Japan). We counted muscle fibers in at least 12 images of sections from 6 slides for each sample using MetaMorph Imaging System (Universal Imaging Corp, U.S.A.) and the fiber numbers were normalized to the muscle fiber area.

Egg and serum analysis. The yolks were separated from the eggs and then homogenized and diluted in ethanol (1:9 in volume). After vortexing, the liquid was centrifuged at $4000 \times g$ for 10 minutes (room temperature). The supernatant was then diluted with ethanol in equal volume for total BA (TBA) detection. TBA, cholesterol, glucose and triglyceride levels were measured by commercial kits from Jiancheng Biological Technology Co., Ltd. (Nanjing, China) according to the manufacturer's instructions with Synergy 2 spectrophotometer (Gene Company, U.S.A.). Detection of serum insulin, insulinlike growth factor 1, triiodothyronine and tetraiodothyronine was performed using kits from Jiuding Medicine Technology Co., Ltd. (Tianjin, China) according to the kit manual, and the results were obtained using HH6003 Radioimmunoassay System (Beijing City, China).

Western blot assay. Gastrocnemius muscle lysates were prepared by grinding samples with a tissue homogenizer in RIPA lysis buffer (Guangzhou, China) containing $1 \mathrm{mM}$ PMSF. After being centrifuged at $12000 \times \mathrm{g}$ for $10 \mathrm{~min}$ at $4^{\circ} \mathrm{C}$, the supernatant was used for determination of total protein concentration using the BCA protein assay kit (Thermo, U.S.A.). Twenty micrograms of protein from each lysate were denatured in SDS loading buffer and centrifuged briefly to remove insoluble components. After being separated by $10 \%$ sodium dodecyl sulphate-polyacrylamide gel electrophoresis, the proteins were transferred to PVDF membranes and then blocked with $5 \%$ (wt/vol) non-fat dry milk in Tris-buffered saline that contained Tween 20 for $2 \mathrm{~h}$ at room temperature. The PVDF membranes were then incubated with the indicated antibodies, including rabbit anti- $\beta$-actin 
A

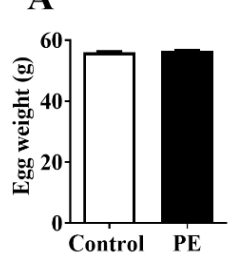

D
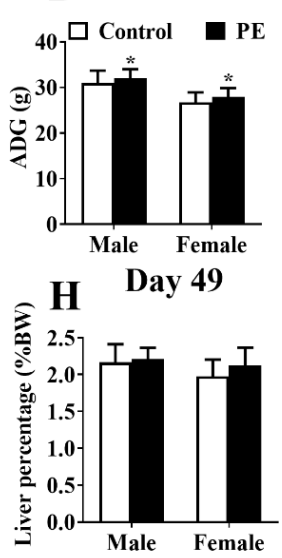

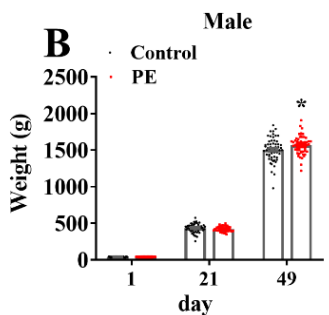

Day 1
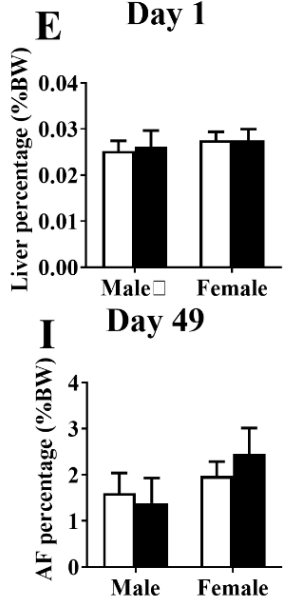
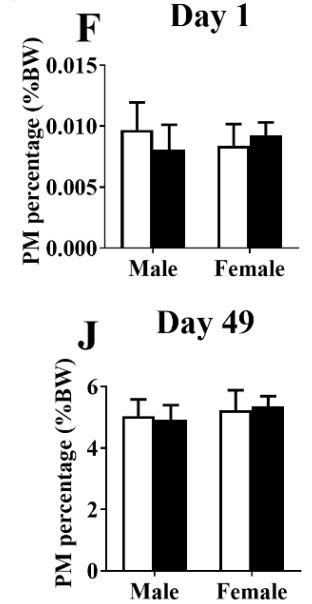

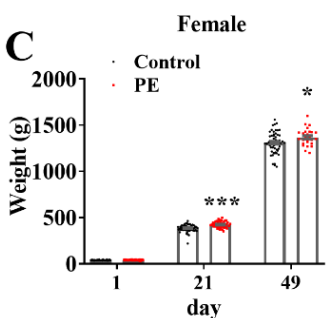

G Day 1

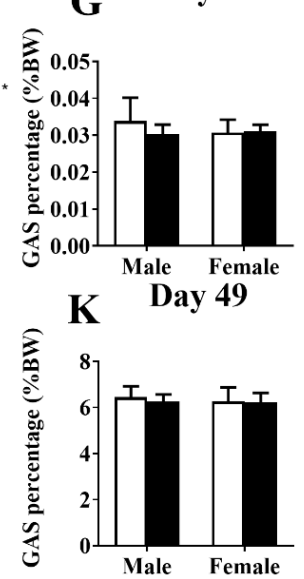

Figure 1. Effect of maternal dietary supplementation of PE on growth performance of the offspring.

(A) The weight of eggs laid by breeder hens ( $n>174$ in each group). (B) Weight of male offspring ( $n=55-60$ in each group). (C) Weight of female offspring ( $n=52-60$ in each group). (D) ADG of male and female offspring ( $n=42-50$ in each group). (E, $\mathbf{F}, \mathbf{G})$ The liver, PM, GAS percentages of male and female offspring on day 1 , respectively $(n=10)$. (H, I, J, K) The liver, AF, PM, GAS percentages of male and female offspring on day 49 , respectively $(n=10)$. ADG, average daily weight gain. PM, pectoralis major. GAS, gastrocnemius AF, abdominal fat. ${ }^{*} p<0.05$ versus control group. ${ }^{* * *} p<0.001$ versus control group.

and rabbit anti-GAPDH (Bioworld Technology, U.S.A.); rabbit anti-FXR (Santa Cruz, U.S.A.), rabbit anti-TGR5 and mouse anti-Decorin (Abcam, U.S.A.); and rabbit anti-MyoD (BD, U.S.A.) and rabbit anti-Myogenin (Cell Signaling Technology, U.S.A.). The primary antibodies were incubated at $4^{\circ} \mathrm{C}$ overnight, with subsequent incubations with the appropriate secondary antibodies (Bioworld Technology, U.S.A.) for $1 \mathrm{~h}$ at room temperature. Images were scanned using a FluorChem M Fluorescent Imaging System (ProteinSimple, U.S.A.) after incubation in BeyoECL Plus kit (Beijing, China). The bands were analysed using ImageJ software (National Institutes of Health, U.S.A.) and normalized to GAPDH/ $\beta$-actin.

Quantitative polymerase chain reaction. RNA was extracted from the liver samples using TRIZOL reagent (Magen, Guangzhou, China) according to the one-step RNA extraction protocol. The cDNA was synthesized from $2 \mu \mathrm{g}$ of RNA using M-MLV Reverse Transcriptase (Promega, Shanghai, China) and oligo-dT18 (Takara, Dalian, China) and incubated at $37^{\circ} \mathrm{C}$ for $1 \mathrm{~h}$ and at $80^{\circ} \mathrm{C}$ for $5 \mathrm{~min}$. Gene quantification was performed by mixing cDNA, SYBR reagent (Toyobo, Osaka, Japan) and the primers listed in Supplementary Table 2 at https://ojs. ptbioch.edu.pl/index.php/abp (Sangon, Guangzhou, China) and running the specific procedures with MX3500P instrument (Applied Biosystems, California, U.S.A) for 35 cycles and $\mathrm{Ct}$ values lower than 32 were considered valid. $\beta$-actin was used as a house-keeping gene and the graph was presented as fold gene changes compared to that of the control group.

Statistics. Data used for graphics were all expressed as the mean \pm S.E.M from two independent experiments, with outliers removed using SPSS 13.0 software.
Every assay was repeated at least two times and we accepted the results only when the coefficient of variation was equal or smaller than $10 \%$. We performed unpaired $t$-test in GraphPad Prism 6.0 to assess the significance of differences between the groups, with $p<0.05$ regarded as statistically significant.

\section{RESULTS}

\section{Maternal dietary PE increased body weight of the offspring}

Body weight of the offspring was recorded, and tissue samples were obtained at different time points after hatching. The results showed that the body weight and average daily weight gain of the offspring increased significantly in the PE group $(p<0.05, p<0.001$ for female body weight on day 21) (Fig. 1B, C, D. The statistical data was supplied in Supplementary Table 3 at https:// ojs.ptbioch.edu.pl/index.php/abp). At the same time, the egg weight showed no difference (Fig. 1A). Additionally, no differences were observed for the relative percentages of liver, pectoralis major, gastrocnemius and abdominal fat on day 1 and 49 for the offspring in our trial (Fig. 1E, F, G and H, I, J, K).

\section{Dietary supplementation of PE stimulated TBA deposition}

After the 4-week trial, the body weight of the hens showed no difference (Supplementary Fig. 3 at https:// ojs.ptbioch.edu.pl/index.php/abp). TBA deposition in eggs and serum of hens was significantly higher in the 

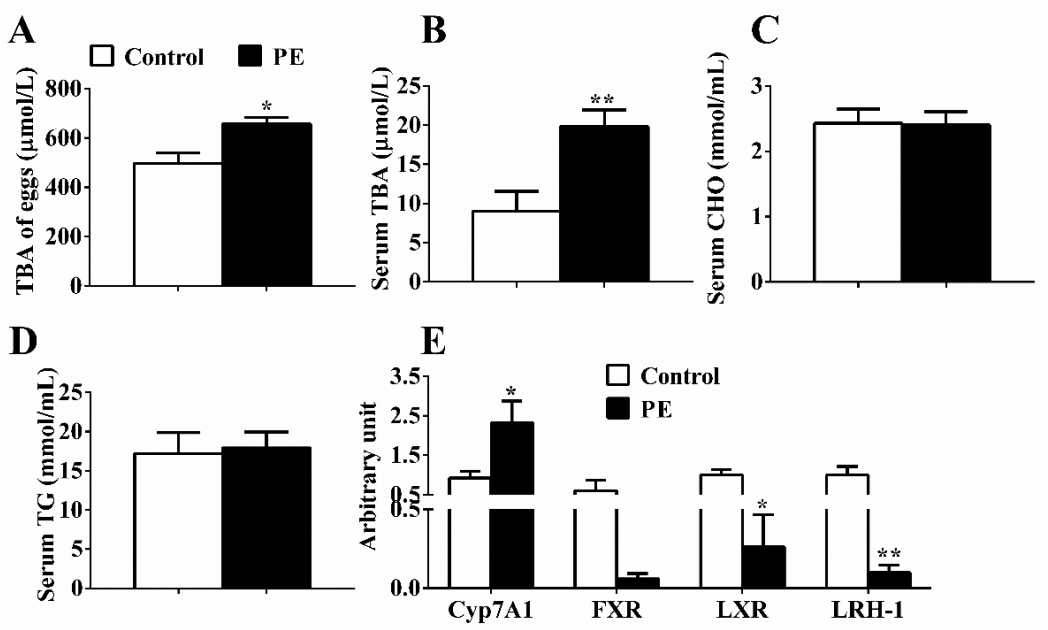

Figure 2. Effect of PE supplementation on serum/egg lipid profile of breeder hens.

(A) TBA concentration in eggs $(n=6)$. (B) Serum TBA concentration $(n=8)$. (C) Serum CHO concentration ( $n=8)$. (D) Serum TG concentration $(n=8)$. (E) The relative mRNA expression of genes involved in bile acid synthesis in the livers of the hens. PE, phytosterol esters; TBA, total BA; CHO, cholesterol; TG, triglycerides; Cyp7A1, cholesterol 7-alpha hydroxylase; FXR, Farnesoid X receptor; LXR, Liver X receptor; $\mathrm{LRH}-1$, liver receptor homolog-1. ${ }^{*} p<0.05$ versus control group. ${ }^{* *} p<0.01$ versus control group.

PE group ( $p<0.05$ and $p<0.01$, respectively) (Fig. 2A, $\mathrm{B})$, while cholesterol and triglyceride levels in serum remained comparable between the two groups (Fig. 2C, D). We also found that the expression of cholesterol 7-alpha-hydroxylase (Cyp7A1) in the hen livers increased $(p<0.05)$, while the expression of liver $\mathrm{X}$ receptor (LXR) and liver receptor homologue 1 (LRH-1) was suppressed significantly $(p<0.05$ and $p<0.01$, respectively). The expression of FXR showed no difference after PE supplementation (Fig. 2E).

\section{Maternal dietary supplementation of PE promoted muscle growth and development of the female offspring}

Immunofluorescence staining of muscle fiber indicated that fiber density in female offspring was significantly higher on day 49 in the PE group $(p<0.05)$ but showed no difference in the male offspring (Fig. $3 \mathrm{~A}$ ). Western blot analysis revealed that the expression of Decorin $(p<0.01)$, MyoD $(p<0.01)$, Myogenin $(p<0.05)$, FXR $(p<0.01)$ and TGR5 $(p<0.01)$ on day 49 as well as the expression of Decorin $(p<0.05)$ and FXR $(p<0.05)$ on day 1 was significantly higher while the expression of TGR5 and Myogenin showed no difference in gastrocnemius protein from female offspring in the PE group (Fig. 3B, C). Interestingly, the expression of these proteins which are crucial for bile acid signalling pathways and muscle development showed no difference in male offspring on day 1 and day 49 time points (Fig. 3B, C). The full gels with these proteins are presented in Supplementary Fig. 2 at https://ojs.ptbioch.edu.pl/index.php/ abp.

\section{DISCUSSION}

In our study, we only found that PE supplementation significantly increased weight gain and body weight of offspring without any change in liver and muscle tissue index. Previous studies also showed a limited difference in food intake and performance after PE supplementation. Dietary supplementation of different doses of phytosterol had no effect on feed intake and conversion of hens (Shi et al., 2014). Dietary supplementation of $1 \%$ soy sterols had no effect on body weight gain, food intake, feed efficiency and egg weight of laying hens in a 4-week trial (Elkin \& Lorenz, 2009). In the mouse model, $2 \%$ of PE supplementation increased body weight gain without a change in food intake for a 16-week feeding period (Bombo et al., 2013) while 8\% of PE increased food intake without a change in body weight gain for a 2 -week period (Brufau et al., 2011). More recently, it has been reported that maternal effect of PE can increase body weight and tibialis anterior muscle index of mouse offspring while promoting lean mass and inhibiting fat mass only in male offspring (Zhao et al., 2019), which also supports our results that male and female offspring were differentially affected by PE. These results suggest that the effect of PE on food intake and body weight gain is determined by the dose and the feeding period. To our surprise, the effect of PE on animal performance has not been reported yet and this effect is probably also related to the dose and the feeding period. Although we found no difference in muscle index in our study, we still investigated the effect of PE on the muscle development of offspring from a molecular aspect to further validate our hypothesis.

Here, we found that both serum $\mathrm{BA}$ of hens and $\mathrm{BA}$ in the egg were promoted by dietary PE. BA homeostasis is maintained by the balance of its synthesis and breakdown, which plays an important role in the regulation of serum BA level. Many external factors introduced by dietary supplementation can affect the level of BA. Dietary Rhodobacter capsulatus stimulated the hepatic metabolism of $\mathrm{BA}$ and reduced the concentration of cholesterol and triglyceride in serum and egg yolk by increasing the excretion of cholesterol, triglyceride and $\mathrm{BA}$ (Salma et al., 2012). Dietary supplementation with $0.10 \%$ lithocholic acid significantly decreased egg production with no effect on egg size, while increasing serum cholesterol level, total egg lipids and egg cholesterol (Edwards et al., 1962). These studies suggest that PE may also regulate nutrient deposition in serum and eggs.

Apart from the poultry model, maternal diet also regulates BA levels of offspring in rodents. Serum total BA level was significantly higher in offspring of lowisoflavone soy protein isolate-fed mothers compared to those of casein-fed mothers (Won \& Kwon, 2018). Al- 


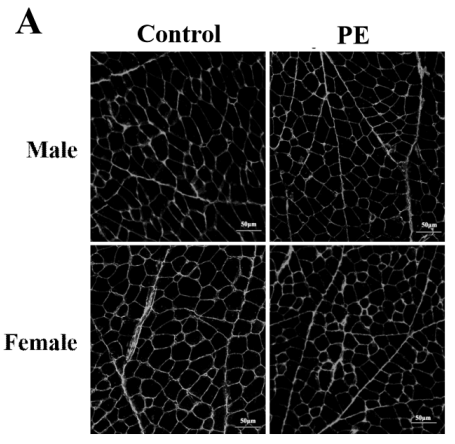

B

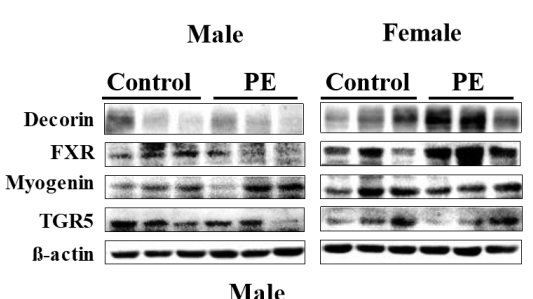

Male
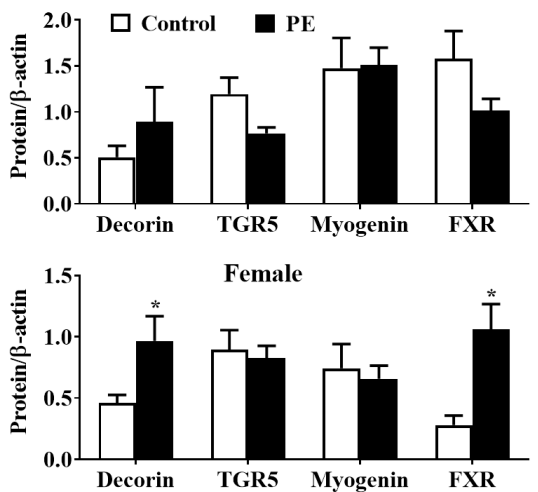

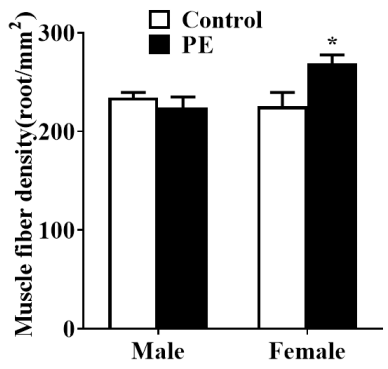

C Male Day 49 Female

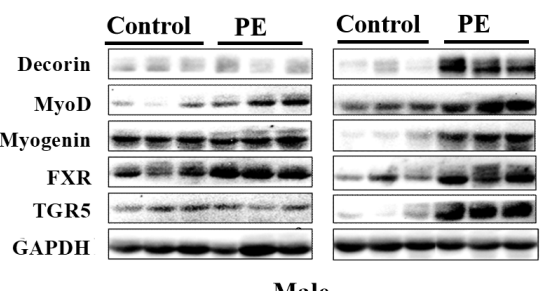

Male
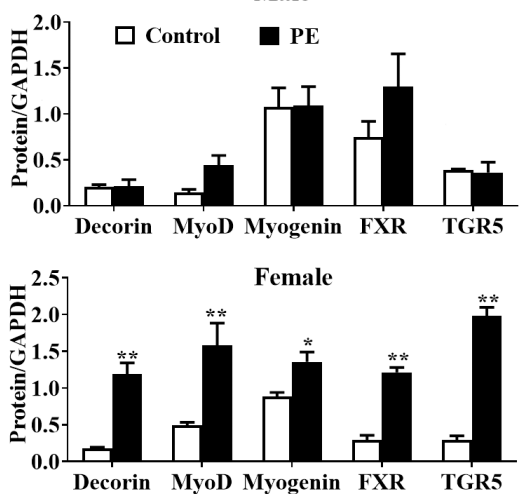

Figure 3. Effect of maternal dietary supplementation of PE on muscle development of offspring.

(A) Immunofluorescence staining of gastrocnemius muscle fiber of the offspring on day $49(\mathrm{n}=6)$. Scale bar, $50 \mu \mathrm{m}$. (B, C) Western blot analysis of Decorin, MyoD, Myogenin, FXR, and TGR5 levels in gastrocnemius of the offspring on day 1 and 49 ( $n=8$ ). $\beta$-actin or GAP$\mathrm{DH}$ served as the loading control. FXR, farnesoid X receptor; TGR5, G protein-coupled bile acid receptor $1 .{ }^{*} p<0.05$ versus control group. ${ }^{* *} p<0.01$ versus control group.

cohol feeding increased BA pool size and decreased BA synthesis related gene expression in mice, with no effect on serum BA level (Donepudi et al., 2018). Phytosterols, which are metabolites of PE, were reported to increase the BA:cholesterol ratio in the bile of dyslipidaemic hamsters (Laos et al., 2014). In addition to the antiinflammatory properties of phytosterols in mouse skin and colon as well as in human patients (De Jong et al., 2008; Medeiros et al., 2007; Vitor et al., 2009), pre-treatment with phytosterols exerted an antioxidant effect on dextran sodium sulphate-induced colonic inflammation by regulation of the intestinal microflora, as indirectly shown by the modification of the BA pattern (Aldini et al., 2014). Interestingly, PE in maternal diet downregulated total BA deposition in serum and amniotic fluid of mice as well as the expression of FXR and Decorin but increased glycolytic muscle fibre formation of offspring probably by promoting Smad3 phosphorylation (Zhao et al., 2019). These studies provide a hint that the nutrients in serum and diet can be deposited into eggs, where BA plays its regulatory role, in different postnatal development stages of chicks, and this phenomenon may be sex-specific. Meanwhile, these studies encouraged us to investigate if the elevation of $\mathrm{BA}$ level can promote muscle development, which is controlled by myogenic proteins, by activation of FXR and Decorin expression in chicks.

In turn, we found that chicks from high-BA-containing eggs grow faster. Skeletal muscle growth and development are modulated by a network of various myogenic regulatory factors, among which myogenin and MyoD have been investigated widely in the literature. A comprehensive review of their functions is provided elsewhere (Zammit, 2017). Decorin is a well-known inhibitor of myostatin, which can promote the proliferation and differentiation of muscle cells (Kishioka et al., 2008; Li et al., 2008). We reported that decorin-induced proliferation of avian myoblasts involves the myostatin/ Smad signaling pathway (Zeng et al., 2014). In this study, expression of decorin on day 49 as well as on day 1 was significantly higher in gastrocnemius from female offspring in the PE group. Therefore, the better growth performance of female offspring is probably due to the stronger inhibition of myostatin by decorin. Thus, it is reasonable that the gastrocnemius of female offspring in the PE group showed significantly higher expression of myogenesis factors (MyoD and Myogenin). 
On the other hand, BA probably participates in the transcription regulation of decorin. TGR 5 and FXR were identified as the cell membrane and nuclear receptors for $\mathrm{BA}$, respectively. They are expressed in many tissues in the body (including skeletal muscle, gut and liver), mediating metabolism and inflammation under different health conditions (Chavez-Talavera et al., 2017). Experiments on human vascular smooth muscle showed that activation of FXR (nuclear receptor of bile acids) promoted expression of decorin (He et al., 2008). Similarly, our previous study proved that the promoter of decorin in myoblast has binding sites for FXR, which can be activated by BA (unpublished data). Therefore, the expression of decorin in skeletal muscle can be probably promoted by BA, and the program of myogenesis and muscle hypertrophy may be activated. Also, it was reported that tauroursodeoxycholic acid can inhibit histone deacetylase and restore insulin action and glucose tolerance in C2C12 cells (Yao et al., 2014). Based on the above studies, we speculated that BA in egg yolk activated FXR and TGR5 in the prenatal and postnatal development stages of chick skeletal muscle and promoted the expression of decorin, and subsequently, myogenin and MyoD. Of course, it would also be interesting to study the gender disparity in the effect of BA on skeletal muscle, which is most likely due to the difference of lipid metabolism in male and female chicks during the prenatal stage.

\section{CONCLUSIONS}

The present study showed that maternal dietary PE supplementation of hens promoted BA deposition in egg yolk and skeletal muscle growth and development of female offspring probably due to the activation of $\mathrm{BA}$ receptors, accompanied by increased expression of decorin, MyoD and Myogenin in skeletal muscles of the offspring.

\section{Conflict of interest}

The authors declare that there is no conflict of interests.

\section{Acknowledgements}

We thank Doctor Shi Wei for his advice and we also appreciate Cantian poultry farm for supplying the field and facilities for the trial. L W wrote the manuscript. X $\mathrm{Z}$ designed the trial plan and performed biological analyses. The corresponding author gave us lots of advice during the trial and manuscript writing. The other authors were also helpful during sampling and analyses. All authors read and approved the final manuscript.

\section{REFERENCES}

Aldini R, Micucci M, Cevenini M, Fato R, Bergamini C, Nanni C, Cont M, Camborata C, Spinozzi S, Montagnani M, Roda G, D'ErricoGrigioni A, Rosini F, Roda A, Mazzella G, Chiarini A, Budriesi R (2014) Antiinflammatory effect of phytosterols in experimental murine colitis model: prevention, induction, remission study. Plos One 9: e108112. https://doi.org/10.1371/journal.pone.0108112

Bombo RP, Afonso MS, Machado RM, Lavrador MS, Nunes VS, Quintao ER, Koike M, Catanozi S, Lin CJ, Nakandakare ER, Lottenberg AM (2013) Dietary phytosterol does not accumulate in the arterial wall and prevents atherosclerosis of LDLr-KO mice. Atherosclerosis 231: 442-447. https://doi.org/10.1016/j.atherosclerosis.2013.10.015

Brufau G, Kuipers F, Lin Y, Trautwein EA, Groen AK (2011) A reappraisal of the mechanism by which plant sterols promote neutral sterol loss in mice. PLoS One 6: e21576. https://doi.org/10.1371/ journal.pone.0021576

Castro FLS, Su S, ChoiH, Koo E, Kim WK (2018) L-Arginine supplementation enhances growthperformance, lean muscle, and bone density but not fat in broiler chickens. Poult Sci 98: 1716-1722. https://doi.org/10.3382/ps/pey504

Chavez-Talavera O, Tailleux A, Lefebvre P, Staels B (2017) Bile acid control of metabolism and inflammation in obesity, type 2 diabetes, dyslipidemia, and nonalcoholic fatty liver disease. Gastroenterology 152: 1679-1694 e1673. https://doi.org/10.1053/j.gastro.2017.01.055

De Jong A, Plat J, Bast A, Godschalk RWL, Basu S, Mensink RP (2008) Effects of plant sterol and stanol ester consumption on lipid metabolism, antioxidant status and markers of oxidative stress, endothelial function and low-grade inflammation in patients on current statin treatment. Eur J Clin Nutr 62: 263-273. https://doi. org/10.1038/sj.ejcn.1602733

Donepudi AC, Ferrell JM, Boehme S, Choi HS, Chiang JYL (2018) Deficiency of cholesterol 7alpha-hydroxylase in bile acid synthesis exacerbates alcohol-induced liver injury in mice. Hepatol Commun 2: 99-112. https://doi.org/10.1002/hep4.1129

Edwards HM, Jr. Jones V, Marion JE (1962) Effect of bile acids on egg production, serum cholesterol and egg cholesterol in hens. J Nutr 77: 253-258. https://doi.org/10.1093/jn/77.3.253

Elkin RG, Lorenz ES (2009) Feeding laying hens a bioavailable soy sterol mixture fails to enrich their eggs with phytosterols or elicit egg yolk compositional changes. Poultry Sci 88: 152-158. https://doi. org/10.3382/ps.2008-00271

He F, Zhang Q, Kuruba R, Gao X, Li J, Li Y, Gong W, Jiang Y, Xie W, Li S (2008) Upregulation of decorin by FXR in vascular smooth muscle cells. Biochem Biophys Res Commun 372: 746-751. https://doi. org/10.1016/j.bbrc.2008.05.098

Hofmann AF, Hagey LR (2014) Key discoveries in bile acid chemistry and biology and their clinical applications: history of the last eight decades. J Lipid Res 55: 1553-1595. https://doi.org/10.1194/jlr. R049437

Jacobs ET, Haussler MR, Alberts DS, Kohler LN, Lance P, Martínez ME, Roe DJ, Jurutka PW (2016) Association between circulating vitamin D metabolites and fecal bile acid concentrations. Cancer Prev Res (Phila) 9: 589-597. https://doi.org/10.1158/1940-6207.CAPR16-0033

Jain D, Ebine N, JiaX, Kassis A, Marinangeli C, Fortin M, Beech R, Hicks KB, Moreau RA, Kubow S, Jones PJ (2008) Corn fiber oil and sitostanol decrease cholesterol absorption independently of intestinal sterol transporters in hamsters. J Nutr Biochem 19: 229-236. https://doi.org/10.1016/j.jnutbio.2007.02.012

Kishioka Y, Thomas M, Wakamatsu J, Hattori A, Sharma M, Kambadur R, Nishimura T (2008) Decorin enhances the proliferation and differentiation of myogenic cells through suppressing myostatin activity. J Cell Physiol 215: 856-867. https://doi.org/10.1002/jcp.21371

Kobayashi Y, Hara N, Sugimoto R, Mifuji-Moroka R, TanakaH, Eguchi A, Iwasa M, Hasegawa H, Iwata K, TakeiY, Taguchi O (2017) The associations between circulating bile acids and the muscle volume in patients with non-alcoholic fatty liver disease (NAFLD). Intern Med 56: 755-762. https://doi.org/10.2169/internalmedicine.56.7796

Kornasio R, HalevyO, Kedar O, Uni Z (2011) Effect of in ovo feeding and its interaction with timing of first feed on glycogen reserves, muscle growth, and body weight. Poult Sci 90: 1467-1477. https:// doi.org/10.3382/ps.2010-01080

Lai W, Huang W, DongB, Cao A, ZhangW, Li J, Wu H, Zhang L (2018) Effects of dietary supplemental bile acids on performance, carcass characteristics, serum lipid metabolites and intestinal enzyme activities of broiler chickens. Poult Sci 97: 196-202. https://doi. org/10.3382/ps/pex288

Laos S, Caimari A, Crescenti A, Lakkis J, Puiggros F, Arola L, del Bas JM (2014) Long-term intake of soyabean phytosterols lowers serum TAG and NEFA concentrations, increases bile acid synthesis and protects against fatty liver development in dyslipidaemic hamsters. Br J Nutr 112: 663-673. https://doi.org/10.1017/ S0007114514001342

Li J, Chen K, Li S, Feng J, Liu T, Wang F, Zhang R, Xu S, Zhou Y, Zhou S, Xia Y, Lu J, Zhou Y, Guo C (2016) Protective effect of fucoidan from Fucus vesiculosus on liver fibrosis via the TGF-beta1/Smad pathway-mediated inhibition of extracellular matrix and autophagy. Drug Des Devel Ther 10: 619-630. https://doi. org/10.2147/DDD'T.S98740

Li X, McFarland DC, Velleman SG (2008) Extracellular matrix proteoglycan decorin-mediated myogenic satellite cell responsiveness to transforming growth factor-beta1 during cell proliferation and differentiation Decorin and transforming growth factor-beta1 in satellite cells. Domest Anim Endocrinol 35: 263-273. https://doi. org/10.1016/j.domaniend.2008.06.002

Lin YG, Meijer GW, Vermeer MA, Trautwein EA (2004) Soy protein enhances the cholesterol-lowering effect of plant sterol esters in cholesterol-fed hamsters. JNutr 134: 143-148. https://doi. org/10.1093/jn/134.1.143 
Medeiros R, Otuki MF, Avellar MC, CalixtoJB (2007) Mechanisms underlying the inhibitory actions of the pentacyclic triterpene alphaamyrin in the mouse skin inflammation induced by phorbol ester 12-O-tetradecanoylphorbol-13-acetate. Eur J Pharmacol 559: 227-235. https://doi.org/10.1016/j.ejphar.2006.12.005

O’Neill FH, Brynes A, Mandeno R, Rendell N, Taylor G, Seed M, Thompson GR (2004) Comparison of the effects of dietary plant sterol and stanol esters on lipid metabolism. Nutr Metab Cardiovasc Dis 14: 133-142. https://doi.org/10.1016/S0939-4753(04)80033-4

SalmaU, Miah AG, Tsujii H, Schellander K, Sudekum KH (2012) Effect of dietary Rhodobacter capsulatus on lipid fractions and egg-yolk fatty acid composition in laying hens. I Anim Physiol Anim Nutr (Berl) 96: 1091-1100. https://doi.org/10.1111/j.1439-0396.2011.01224.x

Schonewille M, Brufau G, Shiri-Sverdlov R, Groen AK, Plat J (2014) Serum TG-lowering properties of plant sterols and stanols are associated with decreased hepatic VLDL secretion. J Lipid Res 55: 2554-2561. https://doi.org/10.1194/jlr.M052407

Shi SR, Shen YR, Chang LL, Zhou CJ, Bo Z, Wang ZY, Tong HB, Zou JM (2014) Safety evaluation of phytosterols in laying hens: effects on laying performance, clinical blood parameters, and organ development. Poult Sci 93: 545-549. https://doi.org/10.3382/ ps.2013-03562

Uni Z, Ferket PR, Tako E, Kedar O (2005) In ovo feeding improves energy status of late-term chicken embryos. Poult Sci 84: 764-770. https://doi.org/10.1093/ps/84.5.764

Vitor CE, Figueiredo CP, Hara DB, Bento AF, Mazzuco TL, Calixto JB (2009) Therapeutic action and underlying mechanisms of a com- bination of two pentacyclic triterpenes, alpha- and beta-amyrin, in a mouse model of colitis. BrJ Pharmacol 157: 1034-1044. https://doi. org/10.1111/j.1476-5381.2009.00271.x

Zhao WJ, Su H, Wang LS, Sun LJ, Luo P, Li YX, Wu HY, Shu G, Wang SB, Gao P, Zhu XT, Jiang QY, Wang LN (2019) Effects of maternal dietary supplementation of phytosterol esters during gestation on muscle development of offspring in mice. Biochem BiophysRes Commun 520: 479-485. https://doi.org/10.1016/j.bbrc.2019.10.056

Won SB, KwonYH (2018) Maternal consumption of low-isoflavone soy protein isolate confers the increased predisposition to alcoholic liver injury in adult rat offspring. Nutrients 10: 332. https://doi. org/10.3390/ nu10030332

Yao XH, Nguyen KH, Nyomba BL (2014) Reversal of glucose intolerance in rat offspring exposed to ethanol before birth through reduction of nuclear skeletal muscle HDAC expression by the bile acid TUDCA. Physiol Rep 2: e12195. https://doi.org/10.14814/ phy2.12195

Zammit PS (2017) Function of the myogenic regulatory factors Myf5, MyoD, Myogenin and MRF4 in skeletal muscle, satellite cells and regenerative myogenesis. Semin Cell Dev Biol 72: 19-32. https://doi. org/10.1016/j.semcdb.2017.11.011

Zeng QJ, Wang LN, Shu G, Wang SB, Zhu XT, Gao P, Xi QY, Zhang YL, Zhang ZQ, Jiang QY (2014) Decorin-induced proliferation of avian myoblasts involves the myostatin/Smad signaling pathway. Poult Sci 93: 138-146. https://doi.org/10.3382/ps.2013-03300 